\title{
Bactericidal Efficacy of ABI-0043, a Novel Rifamycin, in a Murine Pneumococcal Pneumonia Model
}

\author{
Su Young Lee, Pamela R. Tessier, Christopher K. Murphy ${ }^{\dagger}$, David P. Nicolau
}

Received: June 6, 2006 / Accepted: November 20, 2006

(C) Japan Antibiotics Research Association

\begin{abstract}
Novel rifamycins such as ABI-0043, ABI0369, and ABI-0699 had comparable in vivo bactericidal activity with ceftriaxone against a penicillin-G-resistant, mefA-positive Streptococcus pneumoniae in a murine pneumonia model. ABI-0043 demonstrated a dosedependent response with a high correlation to bacterial kill $\left(+0.1\right.$ to $\left.-3.7 \log _{10} \mathrm{CFU}\right)$.
\end{abstract}

Keywords rifamycin, pneumonia, mouse, Streptococcus pneumoniae

Streptococcus pneumoniae is an important bacterial pathogen in pneumonia, meningitis, sinusitis, and otitis media [1]. At least 500,000 cases of pneumonia are estimated to be caused by $S$. pneumoniae every year in the United States [2]. According to a North American surveillance, the current resistant rate of $S$. pneumoniae to penicillin is $16.7 \%$ among community acquired isolates and $12.1 \%$ among hospital acquired isolates [3].

ABI-0043 is a novel rifamycin derivative with potent activity against staphylococci and streptococci [4, 5]. Compared with rifampin, ABI-0043 also has improved activity against rifamycin-resistant strains of these pathogens. This improved activity, however, may not be sufficient to warrant its use as a clinical monotherapeutic agent for systemic infections [6]. Unlike other ansamycins, such as rifampin, ABI-0043 does not significantly induce or inhibit cytochrome P450 enzyme systems in vitro [7].

D. P. Nicolau (Corresponding author), S. Y. Lee, P. R. Tessier, C. K. Murphy: Center for Anti-Infective Research and Development, Hartford Hospital, 80 Seymour Street Hartford, CT 06102-5037,E-mail: dnicola@harthosp.org
For new compounds, like ABI-0043, that have potent antipneumococcal activity in in vitro studies, the assessment of their bactericidal activity in a murine pneumococcal pneumonia model can provide an estimate of future clinical success. This study was reported in part at the 45th Interscience Conference on Antimicrobial Agents and Chemotherapy, Washington, DC, 16 to 19 December 2005.

The purpose of this study was to evaluate the antibacterial activity of ActivBiotics' compounds ABI-0043, ABI-0369 and ABI-0699 in comparison to rifampin and/or ceftriaxone administered intraperitoneally once to thrice daily over time ranging from 6 to 24 hours in the S. pneumoniae murine pneumonia model.

Drug substance of New Chemical Entities (NCE) (ABI-0043, ABI-0369, and ABI-0699) was supplied by ActivBiotics, Inc. (Fig. 1); ceftriaxone was obtained from Roche Pharmaceuticals (Nutley, NJ); rifampin was obtained from Bedford Laboratories (Bedford, $\mathrm{OH}$ ).

Three clinical isolates of $S$. pneumoniae were utilized for in vitro susceptibility testing: one penicillin-G-susceptible (SPN 21), one mefA (SPN 100; penicillin-resistant), and one erm B (SPN 95; penicillin-susceptible) isolate. The phenotypic and genotypic profile for these isolates has been previously confirmed [8 10]. All isolates were maintained in skim milk medium (BD Biosciences, Sparks, Md.) at $-80^{\circ} \mathrm{C}$ and subcultured twice on trypticase soy agar with $5 \%$ sheep blood (BD Biosciences) before use in in vitro and in vivo experiments [8]. MICs of NCEs and rifampin were determined against $S$. pneumoniae strains SPN 21, SPN 95, and SPN 100 in triplicate using standard CLSI (previously

${ }^{\dagger}$ Current address: ActivBiotics, Inc., 128 Spring St., Lexington, MA 02421 USA 

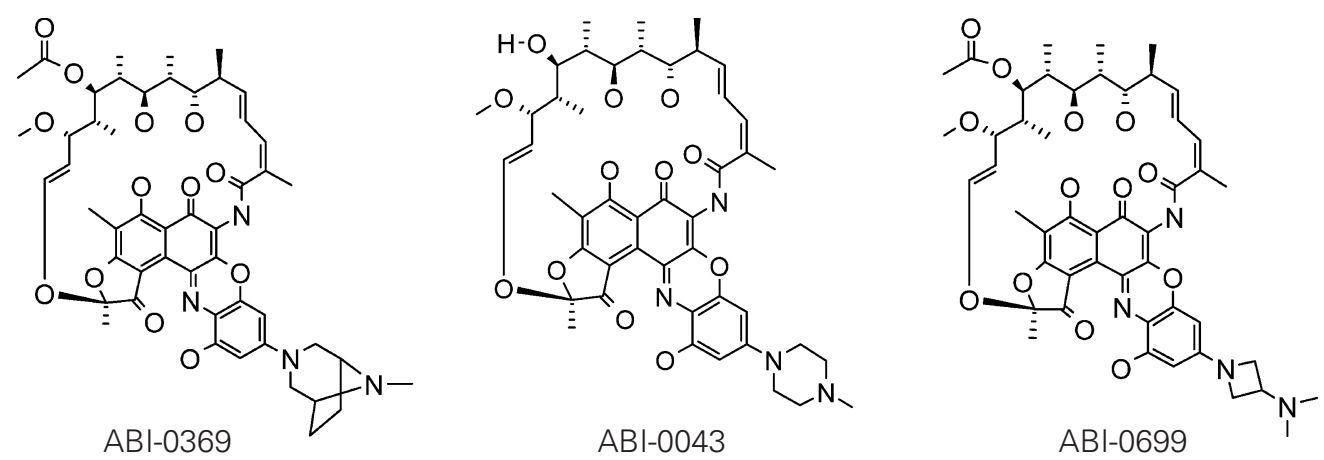

Fig. 1 Chemical structures of rifamycin analogs.

Table 1 MIC $(\mu \mathrm{g} / \mathrm{ml})$ values of study compounds for $S$. pneumoniae isolates

\begin{tabular}{|c|c|c|c|}
\hline \multirow{2}{*}{ Compound } & \multicolumn{3}{|c|}{ SPN strain } \\
\hline & 21 & 95 & 100 \\
\hline Rifampin & 0.06 & 0.06 & 0.015 \\
\hline ABI-0043 & 0.001 & 0.0005 & 0.0005 \\
\hline ABI-0369 & 0.00012 & 0.00025 & 0.00025 \\
\hline ABI-0699 & 0.00025 & 0.00025 & 0.00012 \\
\hline Penicillin $\mathrm{G}^{a}$ & $0.03(S)$ & $0.03 \sim 0.06$ (S) & $4(\mathrm{R})$ \\
\hline Genotypic variations or & Gatifloxacin & ermB & mefA \\
\hline known resistance ${ }^{\mathrm{b}}$ & $\mathrm{MIC}=1 \mathrm{mg} / \mathrm{ml}$ & & \\
\hline
\end{tabular}

a Sensitivity interpretations according to Clinical and Laboratory Standards Institute [9]: S=susceptible; I=intermediate; $\mathrm{R}=$ resistant. ${ }^{\mathrm{b}}$ As reported in references [8] [10].

NCCLS) methods [11]. The in vitro activity of NCEs was superior to that of rifampin and penicillin $\mathrm{G}$ (Table 1) and comparable to that of each other, especially for strains SPN 95 and SPN 100. The penicillin-resistant strain SPN 100 was chosen for in vivo studies.

Specific pathogen-free, female ICR (approximately $22 \mathrm{~g}$ ) mice (Harlan, Inc., Indianapolis, IN) were managed and utilized according to National Research Council recommendations and were provided food and water adlibitum [12]. Mice were rendered neutropenic by IP injection of cyclophosphamide (Cytoxan; Bristol-Myers Squibb, Princeton, N.J.) $150 \mathrm{mg} / \mathrm{kg}$ at four days and $100 \mathrm{mg} / \mathrm{kg}$ at 1 day prior to inoculation [13, 14]. Pneumonia was induced via oropharyngeal inoculation of a $0.05 \mathrm{ml}$ suspension of SPN 100 prepared from an inoculum adjusted to approximately $10^{8} \mathrm{CFU} / \mathrm{ml}$ as described previously [8]. By 8 to 16 hours post inoculation, all animals showed signs of infection including rough coat appearance and limited mobility. IP treatment with antibacterial or normal saline (control) began 12 14 hours post inoculation for groups of 6 mice as follows (also see Fig. 2): QD doses of ABI-0043 at 0.4, 4.0, 40 and $80 \mathrm{mg} / \mathrm{kg}, \mathrm{ABI}-0369$ and ABI-0699 at $80 \mathrm{mg} / \mathrm{kg}$, ceftriaxone at $4.0 \mathrm{mg} / \mathrm{kg}$ and $40 \mathrm{mg} / \mathrm{kg}$ and rifampin at $10 \mathrm{mg} / \mathrm{kg}$. All mice treated QD were sacrificed at 6 hours post treatment. ABI-0043 was also dosed at 120 and $240 \mathrm{mg} / \mathrm{kg} /$ day (q8h, 3 doses of 40 and $80 \mathrm{mg} / \mathrm{kg}$, respectively) and the mice in these groups were sacrificed at 24 hours. The drug vehicle was as follows: $375 \mathrm{~g}$ of Etocas $35 \mathrm{NF}$, $4.4 \mathrm{~g}$ pluronic acid F68, 50.8 g PEG 400, and $10.8 \mathrm{ml}$ of water. Dimethyl sulfoxide (>99.9\%, Sigma-Aldrich Corp., St. Louis, MO) was added to the powder and mixed with vehicle. A group of 6 control mice was sacrificed just prior to initiation of dosing and at the time of lung harvest (at 6 hours for the single dose groups and at 24 hours for groups receiving 3 doses) for each treatment regimen. Lungs were aseptically removed and individually homogenized in $1.0 \mathrm{ml}$ of normal saline as described previously [8]. Serial dilutions of homogenate were plated on trypticase soy agar with 5.0\% sheep blood and subsequently incubated at $35^{\circ} \mathrm{C}$ for 24 


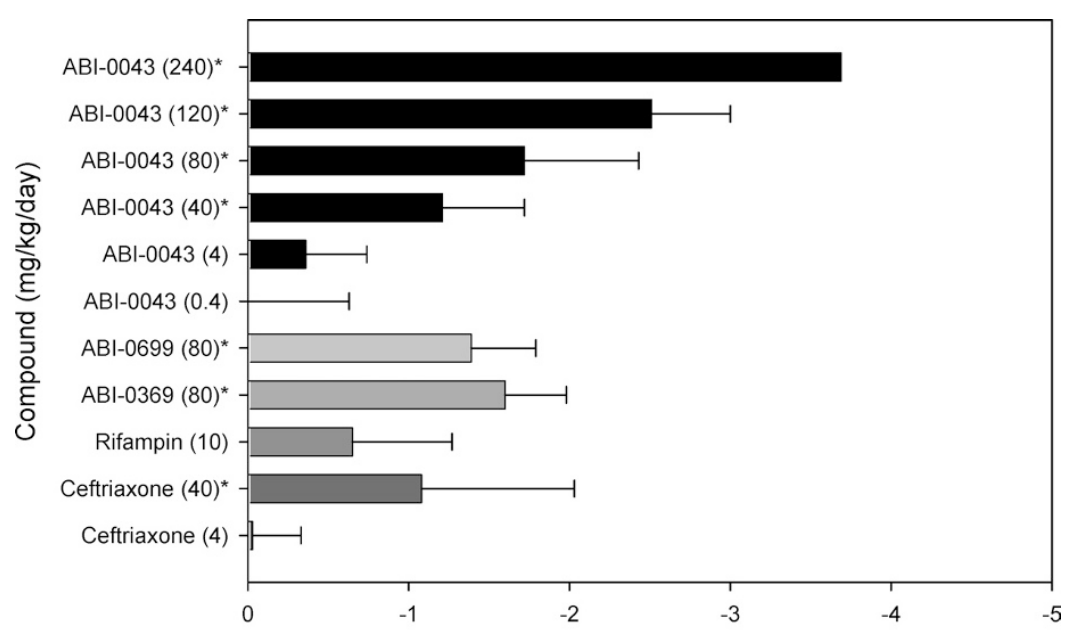

Fig. 2 In vivo antibacterial activity of rifamycin analogs and comparators against SPN100.

${ }^{*} p<0.05$ between $\log _{10}$ CFU changes in infected mice treated with regimens and infected mice treated with placebo (normal saline) $\mathrm{ABI}-0043240 \mathrm{mg} / \mathrm{kg} / \mathrm{day}$ and $120 \mathrm{mg} / \mathrm{kg} /$ day were given as $80 \mathrm{mg}$ q $8 \mathrm{~h}$ and $40 \mathrm{mg}$ q8h. The rest of compounds were given as once daily dose.

hours in $5.0 \% \mathrm{CO}_{2}$ for $\mathrm{CFU}$ determination.

In the untreated control groups, both the 0 and 6 hours CFU levels in lung tissue were consistent between runs, starting at $10^{6}$ to $10^{7} \mathrm{CFU}$ with an increase by about $1 \mathrm{log}$ 24 hours post inoculation. The change in bacterial density in the lung tissues was calculated by subtracting the mean $\log _{10} \mathrm{CFU}$ of the control mice sacrificed just prior to dosing from the mean $\log _{10} \mathrm{CFU}$ of the drug treated and control mice at the end of 6 or 24 hours of therapy. Antibiotic-carry over was observed upon culturing the lung homogenates after the 3 doses of ABI- $004380 \mathrm{mg} / \mathrm{kg} \mathrm{q} 8 \mathrm{~h}$, and as such, the limit of detection was $2 \times 10^{4} \mathrm{CFU}$ for this group.

Fig. 2 displays the change in $\log _{10} \mathrm{CFU} / \mathrm{ml}$ for control and treatment groups. The IP dosing of ABI-0043 produced a dose-dependent killing effect. The bacterial density decreased proportionally with an increase of total dosage when compared with the bacterial density of the same hour control animals $\left(+0.1\right.$ to $\left.-3.7 \log _{10} \mathrm{CFU}\right)$. This relationship was confirmed by analysis of data with WinNonlin 5.0 (Pharsight Co., Cary, NC) and SigmaPlot 2001 (SPSS Inc., Chicago, IL) each of which gave a high correlation $\left(\mathrm{R}^{2}=0.994\right)$.

Statistical analysis was conducted using SigmaStat 2.03 (SPSS Inc., Chicago, IL) with statistical significance defined at $p$-value of 0.05 or less. Mann-Whitney Rank Sum test, t-test, and one-way ANOVA was applied where appropriate. The $40 \mathrm{mg} / \mathrm{kg}$ dose of ABI-0043 showed comparable activity to that of the $40 \mathrm{mg} / \mathrm{kg}$ dose of ceftriaxone $(\mathrm{P}=0.756)$. The $10 \mathrm{mg} / \mathrm{kg}$ dose of rifampin was also similar in efficacy to ABI-0043 at 4 and $40 \mathrm{mg} / \mathrm{kg}$ doses $(\mathrm{P}=0.147)$.

The extent of in vivo antibacterial activity of ABI-0369 and ABI-0699 was similar to that of the ABI-0043 when $80 \mathrm{mg} / \mathrm{kg}$ dose groups were compared $(\mathrm{P}=0.596)$, consistent with both potentially similar PK and the similar MICs determined in this study.

The close correlation between the ABI-0043 daily dosage and change in $\log _{10} \mathrm{CFU}$ in lung tissue suggested that $\mathrm{ABI}-0043$ might have concentration-dependent killing.

In conclusion, these novel rifamycins demonstrated excellent in vitro potency against $S$. pneumoniae having diverse genotypic and phenotypic profiles. In vivo, the NCEs demonstrated significant bacterial killing, which increased in a dose dependent fashion and was similar to ceftriaxone at equal $\mathrm{mg} / \mathrm{kg}$ doses. These data support the continued preclinical development of this class of compounds towards the indication of respiratory infection.

Acknowledgments This work was supported by ActivBiotics Inc., Lexington, MA.

\section{References}

1. Musher DM. Streptococcus pneumoniae. In Principles and Practice of Infectious Diseases, 5th et. Ed., G. Mandell et al., pp. 2128-2147. Churchill Livingstone Inc., New York (2000)

2. Jernigan DB, Cetron MS, Breiman RF. Minimizing the impact of drug-resistant Streptococcus pneumoniae (DRSP). A strategy from the DRSP Working Group. JAMA 275: 206-209 (1996) 
3. Gordon KA, Biedenbach DJ, Jones RN. Comparison of Streptococcus pneumoniae and Haemophilus influenzae susceptibilities from community-acquired respiratory tract infections and hospitalized patients with pneumonia: fiveyear results for the SENTRY Antimicrobial Surveillance Program. Diagn Microbiol Infect Dis 46: 285-289 (2003)

4. Murphy CK, Mullin S, Osburne MS, Duzer J, Siedlecki J, et al. In vitro activity of novel rifamycins against rifamycinresistant Staphylococcus aureus. Antimicrob Agents Chemother 50: 827-834 (2006)

5. Mullin S, Rothstein DM, Murphy CK. Activity of novel benzoxazinorifamycins against rifamycin-resistant Streptococcus pyogenes. Antimicrob Agents Chemother 50: 1908-1909 (2006)

6. Rothstein DM, Farquhar RS, Sirokman K, Sondergaard KL, Hazlett $\mathrm{C}$, et al. Efficacy of novel rifamycin derivatives against rifamycin-sensitive and -resistant Staphylococcus aureus isolates in murine models of infection. Antimicrob Agents Chemother 50: 3658-3664 (2006)

7. Farquhar R, Xia M, Meerts I, Phillips L, Buxton D, Larsson M, Chen Y, Murphy CK, Macneil I. Activity of novel rifamycins in assays for human cytochrome P450 induction. Abstracts of Papers of 45th Intersci Conf on Antimicrob Agents Chemother, F-2048, Washington, DC (2005)

8. Tessier PR, Kim MK, Zhou W, Xuan D, Li C, Ye M, Nightingale $\mathrm{CH}$, Nicolau DP. Pharmacodynamic assessment of clarithromycin in a murine model of pneumococcal pneumonia. Antimicrob Agents Chemother 46: 1425-1434
(2002)

9. Mattoes HM, Banevicius MA, Li D, Turley C, Xuan D, Nightingale $\mathrm{CH}$, Nicolau DP. Pharmacodynamic assessment of gatifloxacin against Streptococcus pneumoniae. Antimicrob Agents Chemother 45: 2092-2097 (2001)

10. Capitano B, Maglio D, Banevicius MA, Nightingale $\mathrm{CH}$, Nicolau DP. Bactericidal effect of cethromycin (ABT-773) in an immunocompetent murine pneumococcal pneumonia model. Intern J Antimicrob Agents 22: 588-593 (2003)

11. Clinical and Laboratory Standards Institute. Methods for dilution antimicrobial susceptibilities tests for bacteria that grow aerobically-Fifteenth Informational Supplement. CLSI/NCCLS document M100-S15. Clinical and Laboratory Standards Institute, 940 West Valley Road, Suite 1400, Wayne, PA. (2005)

12. Institute of Laboratory Animal Research: Guide for the care and use of laboratory animals. National Academy Press, Washington, D.C.

13. Andes D, Craig WA. In vivo activities of amoxicillin and amoxicillin-clavulanate against Streptococcus pneumoniae: application to breakpoint determinations. Antimicrob Agents Chemother 42: 2375-2379 (1998)

14. Joly-Guillou ML, Wolff M, Pocidalo JJ, Walker F, Carbon C. Use of a new mouse model of Acinetobacter baumannii pneumonia to evaluate the post-antibiotic effect of imipenem. Antimicrob Agents Chemother 41: 345-351 (1997) 